First author

( corresponding author)

Dr. Kamel Saleh

EE Dept

An-Najah National University

West Bank

Palestine

kamel.saleh@najah.edu

Second author

Prof. Mark Sumner

EE Dept

Nottingham University

Nottingham

UK 


\section{Sensorless Speed Control of a Fault-tolerant Five-phase PMSM Drives \\ Abstract}

This paper introduces a novel method to achieve sensorless speed control of a Five-phase Permanent Magnet Synchronous Motor (PMSM) drive in case of a single-phase open-circuit fault regardless which phase is open. The motor performance when an open circuit fault occurs is as good as it is before the fault. The degradation in motor performance, when an open circuit fault occurs, is minimized due to implementing a novel control technique that is using the four remaining healthy currents. This strategy includes introducing two software modifications to the operation of the five motor post the fault. Firstly, an asymmetric SVPWM is used post the fault instead of multi-dimension SVPWM that is used before the fault. Secondly, a new algorithm is introduced to track the saliency post the fault. The new algorithm is considering the application of the new modulation technique. Moreover, it uses only the excitation in the healthy currents of the motor due to the IGBT switching actions. Simulation results presented in this paper shows that the performance of the motor over a wide speed range and at different load conditions is maintained post the fault.

Keywords: Sensorless, five-phase motor, multi-dimension SVPWM, open circuit fault .asymmetric SVPWM

\section{Introduction}

Multi-phase motor drives are witnessing an increasing interest in research and in the industry in recent years. The multi-phase motors have higher reliability, better efficiency, higher torque density, and lower torque pulsation compared to classical three-phase machines s [1,2]. Due to previous features, multi-phase motor drives are starting replacing three motor drives in the applications such as electrical vehicles, electric craft, electrical ships and high power applications. There are many techniques that are proposed to control five-phase under healthy operating conditions such as scalar control [3], vector control [4], direct torque control [5], model predictive control [6]. And sensorless control [7-8] and multi-dimension SVPWM [912].

To maintain the performance of the five-phase motor drive post the fault, optimal current control is usually employed to control the current in the healthy phases to ensure certain optimization criteria including minimum torque ripples, equal phase currents, and minimum copper losses [13-15]. This can be achieved by implementing a fault-tolerant technique post the fault. Fault tolerant techniques can be divided into two primary groups: 1) control system based [16-20] and 2) inverter configuration based [21-25]. Sensorless control of a multi-phase motor drive post an open circuit fault is introduced in [26] only.

The novelty in this paper is that it proposes a sensorless-fault-tolerant control technique of a five-phase PMSM drive that enables the five-phase motor to continue operating in the case of single-phase open-circuit fault without introducing and hardware modification. The performance of this drive under an open-circuit fault is at the same quality as the performance under healthy operating condition. This will increase the reliability of the system.

\section{Research method}

\section{1 five-phase drive topology}

Figure 1 shows the topology of the five-phase motor drive used in this work [12]. The five-phase motor can be modeled according to the equations below.

$$
\left[\begin{array}{c}
\mathrm{v}_{a} \\
\mathrm{v}_{b} \\
\mathrm{v}_{c} \\
\mathrm{v}_{d} \\
\mathrm{v}_{e}
\end{array}\right]=\left[\begin{array}{l}
r_{s a} \\
r_{s b} \\
r_{s c} \\
r_{s d} \\
r_{s e}
\end{array}\right] *\left[\begin{array}{l}
i_{a} \\
i_{b} \\
i_{c} \\
i_{d} \\
i_{e}
\end{array}\right]+\left[\begin{array}{l}
d \emptyset_{a} / d t \\
d \emptyset_{b} / d t \\
d \emptyset_{c} / d t \\
d \emptyset_{d} / d t \\
d \emptyset_{e} / d t
\end{array}\right]
$$

Where $\mathrm{v}_{a, b, c, d, e}$ are the stator phase voltages, $r_{s a, b, c, d, e}$ are the stator resistances, $i_{a, b, c, d, e}$ are the stator phase currents,$\emptyset_{a, b, c, d, e}$ are the fluxes linking each stator coil. The formulas of these fluxes are given in equation (2).

$$
,\left[\begin{array}{l}
\emptyset_{a} \\
\emptyset_{b} \\
\emptyset_{c} \\
\emptyset_{d} \\
\emptyset_{e}
\end{array}\right]=\left[\begin{array}{lllll}
L_{a a} & L_{a b} & L_{a c} & L_{a d} & L_{a e} \\
L_{a b} & L_{b b} & L_{b c} & L_{b d} & L_{b e} \\
L_{a c} & L_{b c} & L_{c c} & L_{c d} & L_{c e} \\
L_{a d} & L_{b d} & L_{c d} & L_{d d} & L_{d e} \\
L_{a e} & L_{b e} & L_{c e} & L_{d e} & L_{e e}
\end{array}\right] *\left[\begin{array}{c}
i_{a} \\
i_{b} \\
i_{c} \\
i_{d} \\
i_{e}
\end{array}\right]+\left[\begin{array}{l}
\emptyset_{m a} \\
\emptyset_{m b} \\
\emptyset_{m c} \\
\emptyset_{m d} \\
\emptyset_{m e}
\end{array}\right]
$$


where $L_{a a}, L_{b b}, L_{c c}, L_{d d}$ and $L_{e e}$ are the stator coils self-inductances, $L_{a b}, L_{b a}, L_{c a}, L_{a c}, L_{a d}, L_{d a}$, $L_{a e}, L_{e a}, L_{b c}, L_{c b}, L_{b d}, L_{d b}, L_{b e}, L_{e b}, L_{c d}, L_{d c}, L_{c e}, L_{e c}, L_{e d}$ and $L_{d e}$ are the mutual inductances between stator coils and $\emptyset_{m a, b, c, d, e}$ are the fluxes linking the stator coils due to the rotor permanent magnet. The equations of the self and mutual inductance are given in equations (3-4).

$\left[\begin{array}{l}L_{a a} \\ L_{b b} \\ L_{c c} \\ L_{d d} \\ L_{e e}\end{array}\right]=\left[\begin{array}{l}L_{s o} \\ L_{s o} \\ L_{s o} \\ L_{s o} \\ L_{s o}\end{array}\right]+L_{x} *\left[\begin{array}{c}\cos (2 \theta) \\ \cos \left(2 \theta-72^{\circ}\right) \\ \cos \left(2 \theta-144^{\circ}\right) \\ \cos \left(2 \theta-216^{\circ}\right) \\ \cos \left(2 \theta-288^{\circ}\right)\end{array}\right]$

$\left[\begin{array}{l}L_{a b}=L_{b a} \\ L_{a c}=L_{c a} \\ L_{a d}=L_{d a} \\ L_{a e}=L_{e a} \\ L_{b c}=L_{c b} \\ L_{b d}=L_{d b} \\ L_{b e}=L_{e b} \\ L_{c d}=L_{d c} \\ L_{c e}=L_{e c} \\ L_{d e}=L_{e d}\end{array}\right]=L_{s o} *\left[\begin{array}{c}\cos \left(72^{\circ}\right) \\ \cos \left(144^{\circ}\right) \\ \cos \left(216^{\circ}\right) \\ \cos \left(288^{\circ}\right) \\ \cos \left(72^{\circ}\right) \\ \cos \left(144^{\circ}\right) \\ \cos \left(216^{\circ}\right) \\ \cos \left(72^{\circ}\right) \\ \cos \left(144^{\circ}\right) \\ \cos \left(72^{\circ}\right)\end{array}\right]+L_{x} *\left[\begin{array}{c}\cos \left(2 \theta-72^{\circ}\right) \\ \cos \left(2 \theta-144^{\circ}\right) \\ \cos \left(2 \theta-216^{\circ}\right) \\ \cos \left(2 \theta+288^{\circ}\right) \\ \cos \left(2 \theta-216^{\circ}\right) \\ \cos \left(2 \theta-288^{\circ}\right) \\ \cos (2 \theta) \\ \cos (2 \theta) \\ \cos \left(2 \theta-72^{\circ}\right) \\ \cos \left(2 \theta-144^{\circ}\right)\end{array}\right](4)$

Where $L_{x}$ represents the fluctuation of the stator inductance and $L_{s o}$ represents the average mutual inductance. The term $(2 \theta)$ in the above equations represents the saturation saliency.

Finally, the flux linking the stator coils due to the rotor magnets are:

$\left[\begin{array}{l}\emptyset_{m a} \\ \emptyset_{m a} \\ \emptyset_{m a} \\ \emptyset_{m a} \\ \emptyset_{m a}\end{array}\right]=\Lambda_{m} *\left[\begin{array}{c}\cos (2 \theta) \\ \cos \left(2 \theta-72^{\circ}\right) \\ \cos \left(2 \theta-144^{\circ}\right) \\ \cos \left(2 \theta-216^{\circ}\right) \\ \cos \left(2 \theta-288^{\circ}\right)\end{array}\right](5)$, where $\Lambda_{m}$ is the peak flux linkage due to permanent magnet.

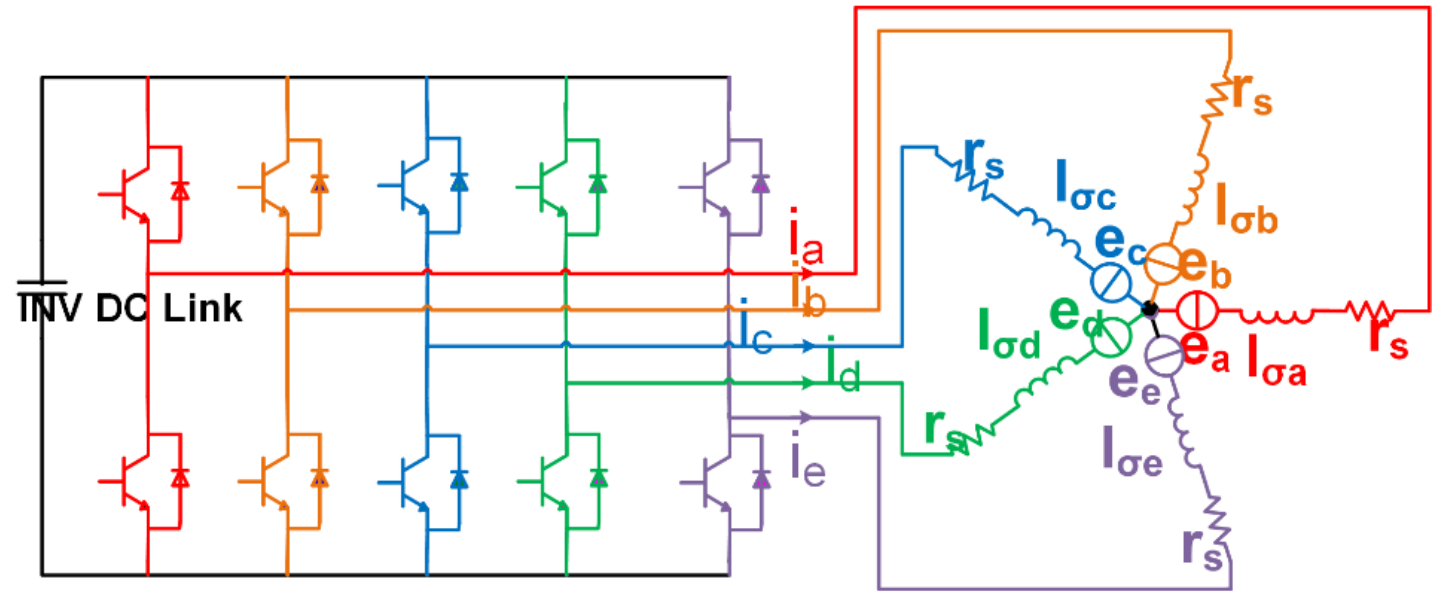

Figure 1. Five phase drive.

2.2 Normal operation of a five-phase drive

The classical space vector pulse width modulation technique that is used in a three-phase motor drive can't be applied in five-phase motor drive. This is due to the fact that this modulation technique will generate voltages at the output of the five-phase inverter that has a third harmonic component. This third harmonic voltage component will generate a third harmonic current component that does not produce any rotating MMF (not electro-mechanical energy conversion related). And so, even the inverter generates a very small third harmonic voltage, a large third harmonic component will be circulating in the motor stator windings. It is, therefore, important that the five-phase inverter output is kept as close as possible to sinusoidal i.e the third harmonic component in the output voltage of the inverter should be controlled to zero. This can be done by mapping the reference voltage into two orthogonal planes either stationary $(\alpha 1-\beta 1$ and $\alpha 3-\beta 3)$ or rotating at synchronous speed and 3 times the synchronous speed (d1-q1 and d3-q3) respectively [9-12]. 
This allow controlling the fundamental and the third harmonic components of the voltage generated by the inverter independently as shown in Figure 2.

Figure 3 illustrates the multi-dimension SVPWM modulation technique. In this example, the reference voltage V_ref exists in the third sector. The mapping of V_ref into the $\alpha 1-\beta 1$ plane and into the $\alpha 3-\beta 3$ is illustrated. Then the adjacent vectors $(00000,01000,01100,11100,11110,11111)$ are used to generate the fundamental and the third component of the reference voltage.
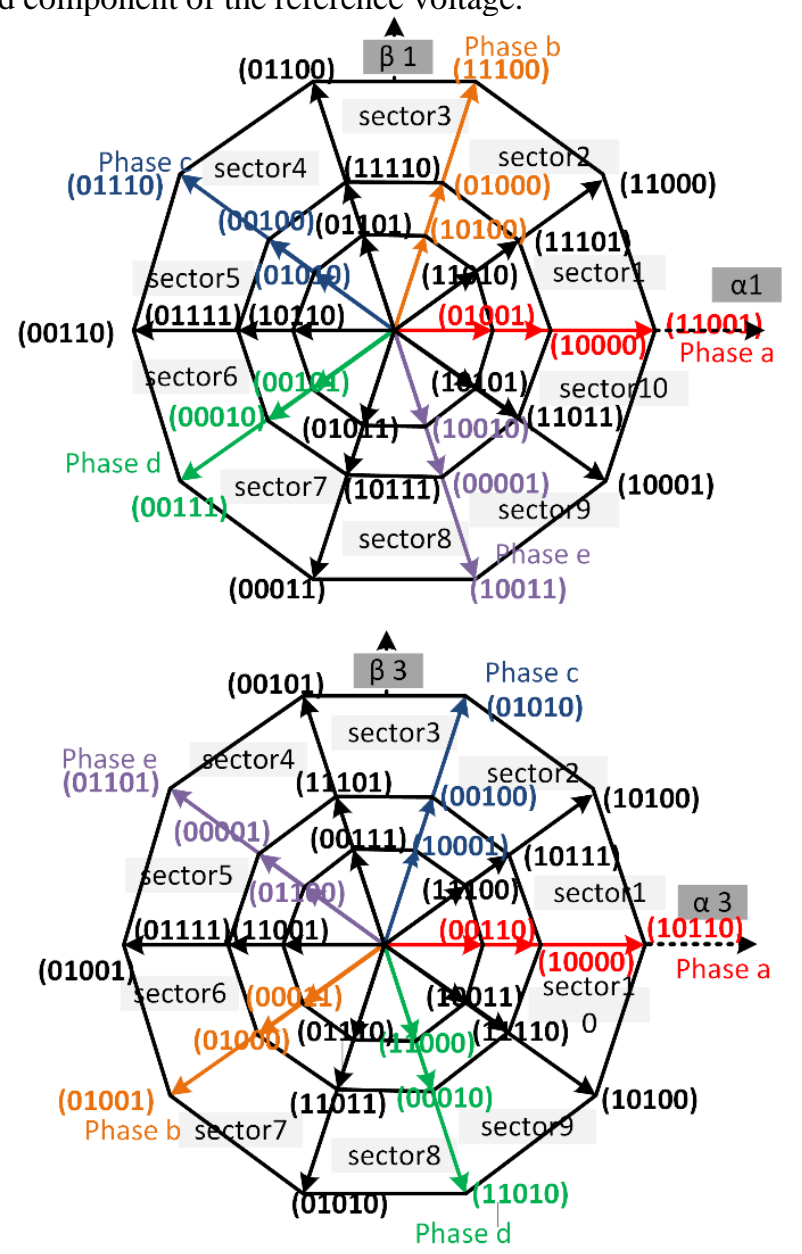

Figure 2. multi-dimension SVPWM.
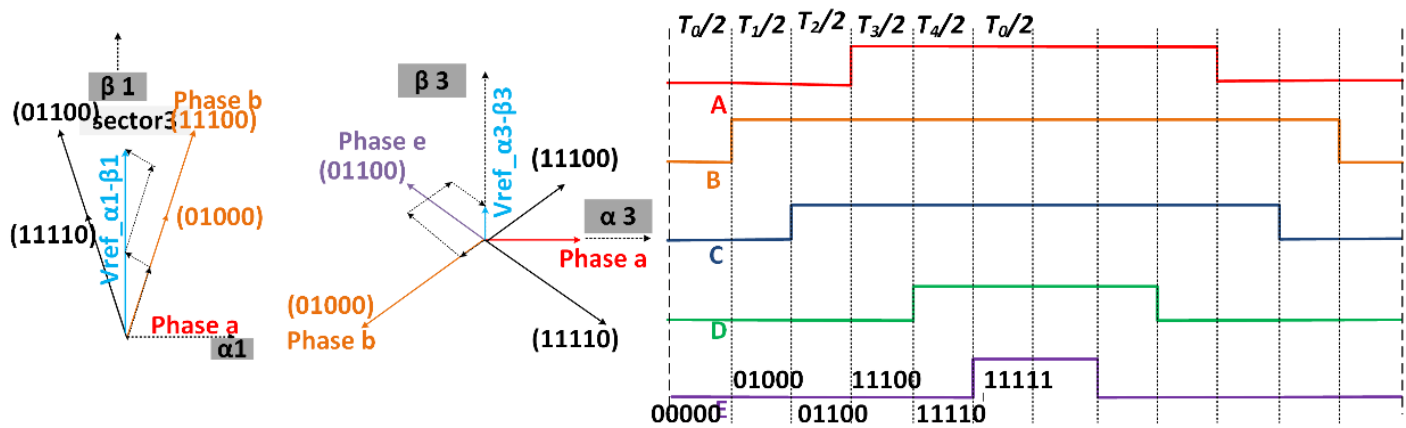

Figure 3. Reference voltage mapping into $\alpha 1-\beta 1, \alpha 3-\beta 3$ plane plans.

\subsection{Post-fault operation of a five-phase drive}

Vector control of five-phase motor drive under healthy condition guarantees equal magnitudes of the stator currents and equal phase shifts of $\frac{2 \pi}{5}$ between them. If an open-circuit fault is introduced to one phase of the five-phase motor then the remaining healthy phases are usually controlled to ensure equal stator phase currents, minimum machine torque ripples and maximum torque production and nullifying the fundamental negative sequence $[24,25]$. This done by shifting the two healthy stator currents adjacent to the faulted current by $\frac{\pi}{5}$ and making the amplitudes of all healthy currents to equal $138.2 \%$ as shown in Figure 4. 




(a)

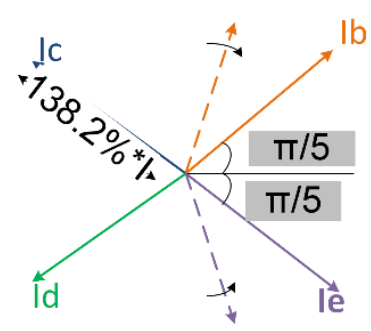

(b)

\subsubsection{Asymmetric SVPWM}

To maintain the operation of a five-phase motor drive post the fault, the asymmetric SVPWM method is used [18]. This method is based on obtaining a new space vector diagrams that consider the change in amplitude and phase angle of the remaining healthy currents post the fault as shown in figure 5.a, figure 5.b, figure 5.c, figure 5.d and figure 5.e respectively. The space vector diagrams consist of vectors of different amplitudes like 0.4 VDC, 0.4702 VDC and 0.6472 VDC which are calculated according to formula below [18]:-

$V_{S}=\frac{2}{5} * V D C *\left(S_{b} * e^{j * \frac{\pi}{5}}+S_{c} * e^{j * \frac{4 \pi}{5}}+S_{d} * e^{-j * \frac{4 \pi}{5}}+S_{e} * e^{j * \frac{\pi}{5}}\right)$

Where $S_{b}, S_{c}, S_{d}$, and $S_{e}$ are the gating signals of the switches in phase 'b', 'c','d' , and 'e' respectively.



(a)

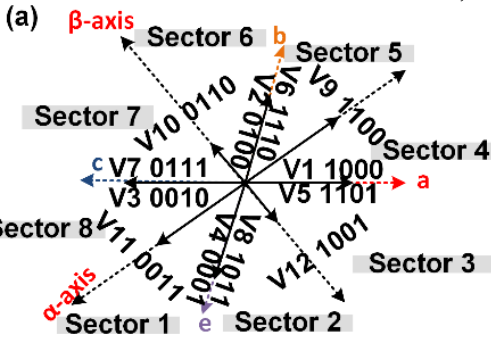

(d)

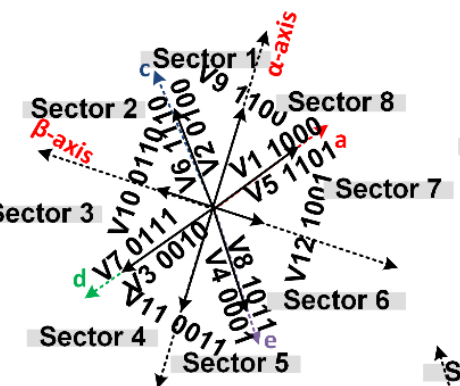

(b)

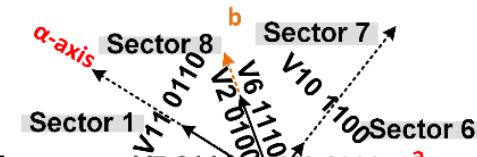

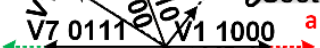

d 330010 - 351101
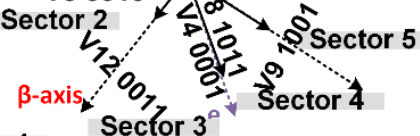

(c)

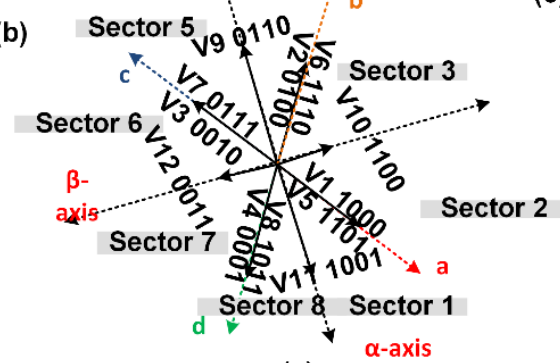

(e)

Figure 5 space vector diagrams when an open circuit fault is introduced in: (a) phase-'a', (b) phase- 'b', (c) phase - 'c', (d) phase -'d' and (e) phase - 'e'.

Regardless in which phase the fault is introduced and in which sector the voltage exists, the adjacent vector three active vectors $(0.4 * \mathrm{VDC}$ and either $0.4702 * \mathrm{VDC}$ or $0.6472 * \mathrm{VDC})$ and two null vectors (1111 and $0000)$ are used to utilize the reference voltage. Figure 6 shows the reference voltage (Vref_ $\alpha-\beta)$ that exists in the second sector in space vector diagram 5.c. All the adjacent vectors $(\mathrm{V} 3=0010, \mathrm{~V} 12=0011, \mathrm{~V} 7=0111$ , $\mathrm{V} 0=1111)$ are used to generate the reference voltage ( $\mathrm{V} \_$ref) as shown in figure 6 . The dwell times can be obtained as follows:-

$$
\begin{aligned}
& V_{\alpha}=V_{\text {ref }} * \cos (\theta) \quad \text { (7) }, V_{\beta}=V_{\text {ref }} * \sin (\theta) \quad(8), V_{1}=V_{\alpha} * \sin \left(\frac{\pi}{5}\right)-V_{\beta} * \cos \left(\frac{\pi}{5}\right) \text { (9) } \\
& T 1=\frac{V_{\beta}}{0.4 * V D C * \sin \left(\frac{\pi}{5}\right)} * T s \quad(10), T 2=\frac{V_{1}}{0.6472 * V D C * \sin \left(\frac{\pi}{5}\right)} * T s(11) \text { and } \mathrm{T} 0=\mathrm{Ts}-\mathrm{T} 1-\mathrm{T} 2 \quad \text { (12) where Ts } \\
& \text { is the sampling period [18]. }
\end{aligned}
$$



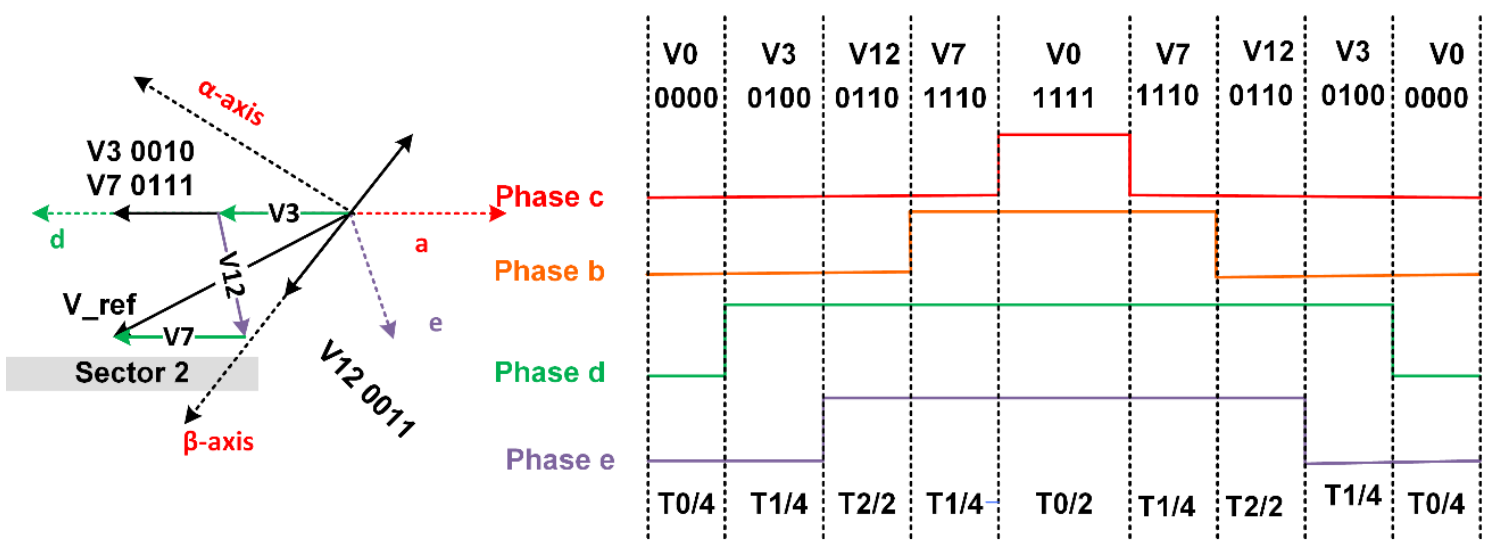

Figure 6 Asymmetric SVPWM waveform in case case of an open-circuit fault in phase'c' and the reference voltage vector located in sector 2 .

Figure 7 shows the vector control technique that is simulated in the SABER simulator. This control technique is using multi-dimension SVPWM in the healthy operating condition of the PMSM motor. If an open-circuit fault is introduced to any phase of the motor, the asymmetric SVPWM is applied using a switch.

The results from the above test are shown in figure 8 . The motor was loaded by $50 \%$ and running at 100 $\mathrm{rpm}$ in the healthy condition. In time interval ( $2 \mathrm{~s}-3 \mathrm{~s})$ an open circuit fault is introduced to phase ' $\mathrm{a}$ ' and at the same time, an asymmetric SVPWM was applied. Figure 8 shows that the stator current in phase ' $a$ ' became zero. In addition to that, the magnitudes of the currents in phases ' $b$ ', 'c', 'd', and 'e' were increased by $38.2 \%$ and the phase currents in phases ' $b$ ' and ' $e$ ' are shifted by $36^{\circ}$ towards phase 'a'. these results are identical to those shown in figure 4 . Similar results can be obtained in intervals $(4 s-5 s),(6 s-7 s),(8 s-9 s)$ and (10s to 11s) where an open- circuit faults in phases ' $b$ ', ' $c$ ', ' $d$ 'and 'e' were introduced to the operation of the motor respectively and at the same time an asymmetric SVPWM were applied. Outside these intervals, the fault was removed and the motor returned to run in healthy operating conditions using multi-dimension SVPWM. The results show that the quality of the performance of the system is maintained during the faults.



Figure 7 fault-tolerant control topology for a five phase drive in sensor mode. 

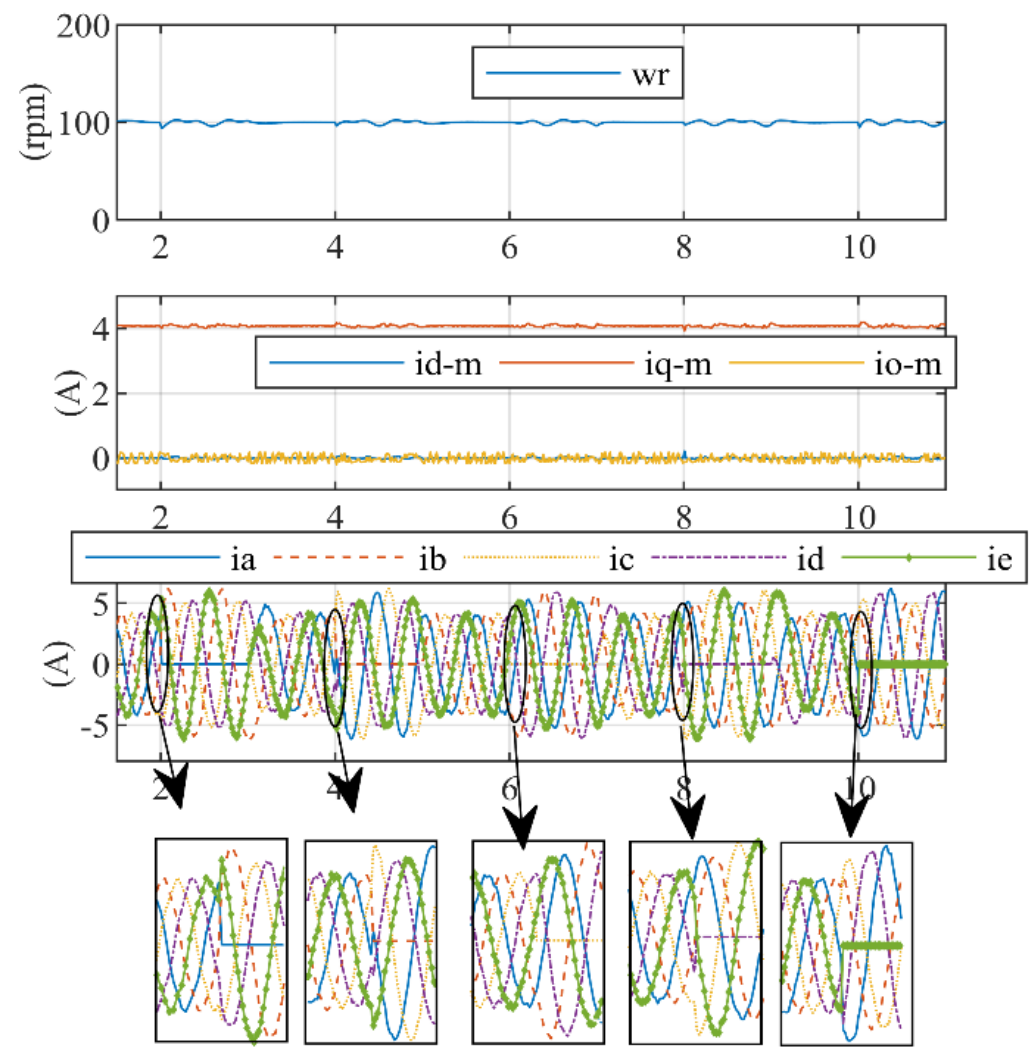

Figure 8 results for the fault-tolerant five-phase motor drive in sensor mode.

\subsubsection{Post-fault algorithm for tracking the saliency}

The algorithm that is proposed in [7,8] to track the saturation saliency of a five-phase motor drive running under healthy operating conditions is no longer valid to be applied in case of an open-circuit fault as shown in figure 9 . In time intervals when the motor was running in normal operating conditions, the algorithm proposed in $[7,8]$ worked fine and the saturation saliency could be tracked. Unfortunately, this was not the case post the fault as shown in time intervals $(2 s-3 s),(4 s-5 s),(6 s-7 s),(8 s-9 s)$ and $(10 s-11 s)$. In these time intervals the position scalars pa,pb,pc,pd and pe were corrupted and the saliency position couldn't be obtained from them anyway.

To illustrate the above results an example is considered in which the motor running is running under the condition where phase ' $a$ ' is lost and the reference voltage exists in sector four as an example. According to $[7,8]$ the equations to obtain the position signals are give as: $p a=\frac{d i_{d}^{(V 1)}}{d t}-\frac{d i_{d}^{(V 0)}}{d t}, p b=\frac{d i_{d}^{(V 0)}}{d t}-$ $\frac{d i_{d}^{(V 4)}}{d t}, \mathrm{p} c=\frac{d i_{a}^{(V 0)}}{d t}-\frac{d i_{a}^{(V 4)}}{d t}$ and $\mathrm{p} e=\frac{d i_{b}^{(V 1)}}{d t}-\frac{d i_{a b}^{(V 0)}}{d t}$. From these equations, it is clear that in order to obtain $\mathrm{p} c$, the dynamic responses of phase'a' due to applying V4 and V0 should be used while these values are zero since an open-circuit fault is introduced to phase ' $a$ '. And Hence $p c$ will be zero. Similar results will be obtained in different sectors and different faulted phases because this method is proposed to work in healthy mode when all the currents are healthy. To obtain the saliency position in a five-phase PMSM drive post the fault, a new equivalent circuit for the motor should be considered that reflects the loss of one phase of the five motor in addition to use Asymmetric SVPWM .

Figure 10 shows the Asymmetric SVPWM for a five-phase inverter post a fault in phase ' $a$ ' and when V_ref exists in the fourth sector. The PWM waveforms are shown in Figure 10. 

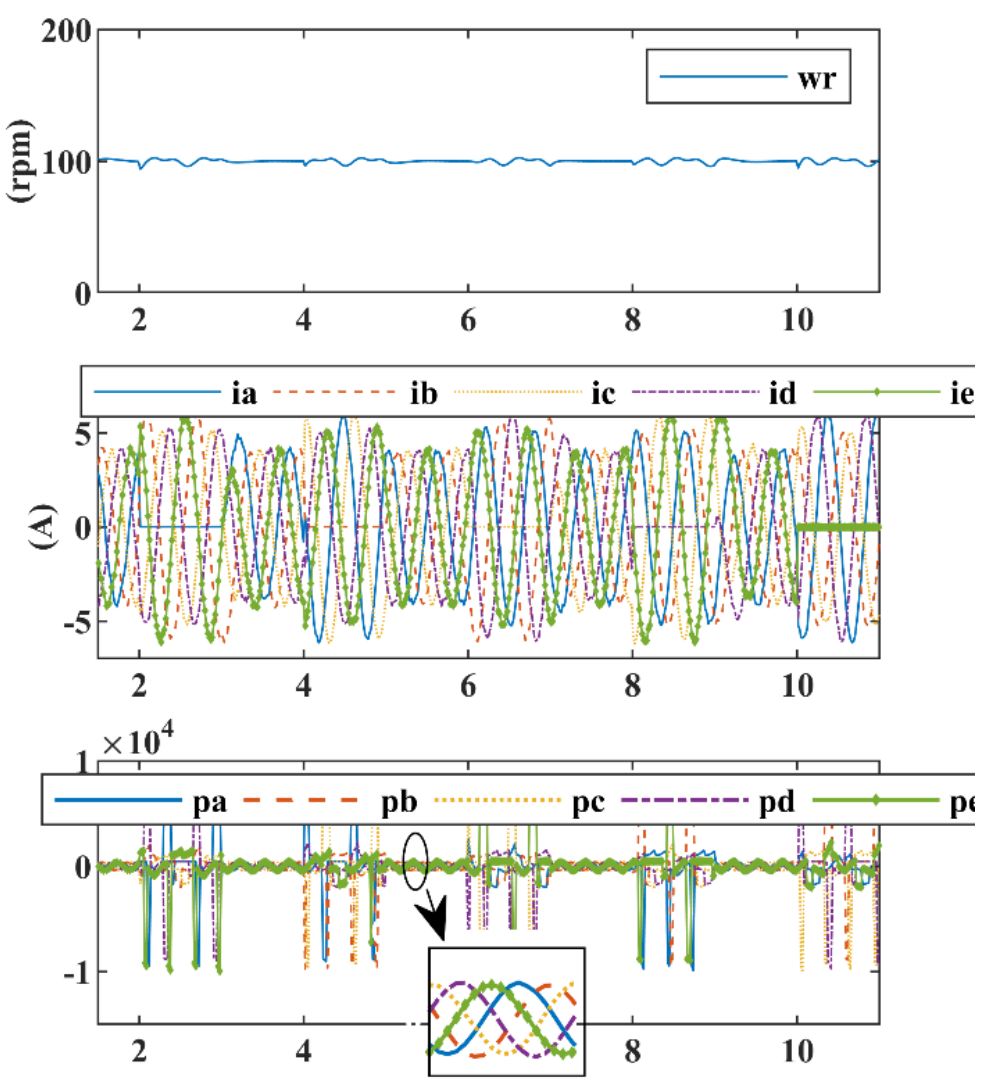

Figure 9 Tracking the saturation saliency in healthy mode and post the fault mode using the algorithm proposed K. Saleh and M. Sumner in 2016 and 2018.

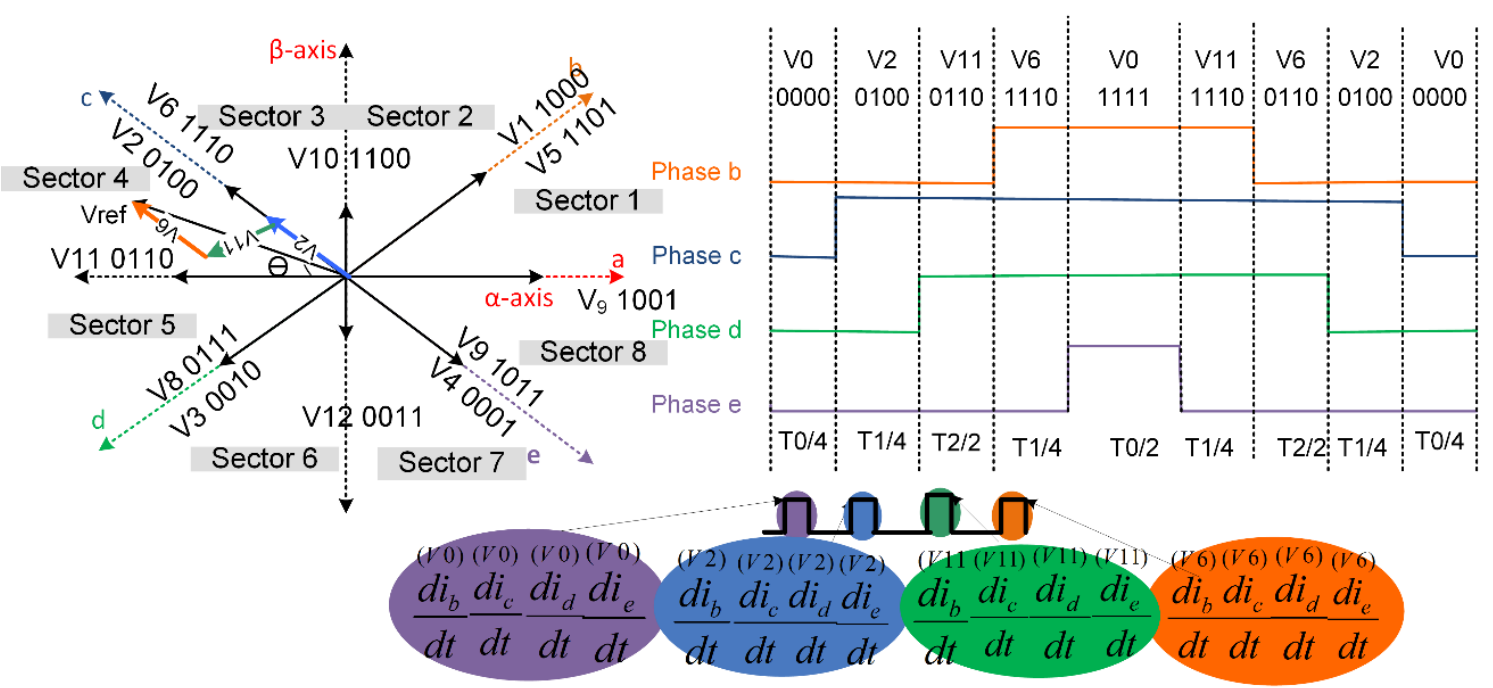

Figure 10. Sampling instant of the currents transient responses in case of open-circuit fault in phase 'a'.

Figure 11a, figure 11.b ,figure 11.c and figure 11.d show respectively the stator circuits of five-phase PM motor under an open circuit fault in phase 'a' when the vectors V0, V2,V11 and V6 are applied 
(a)
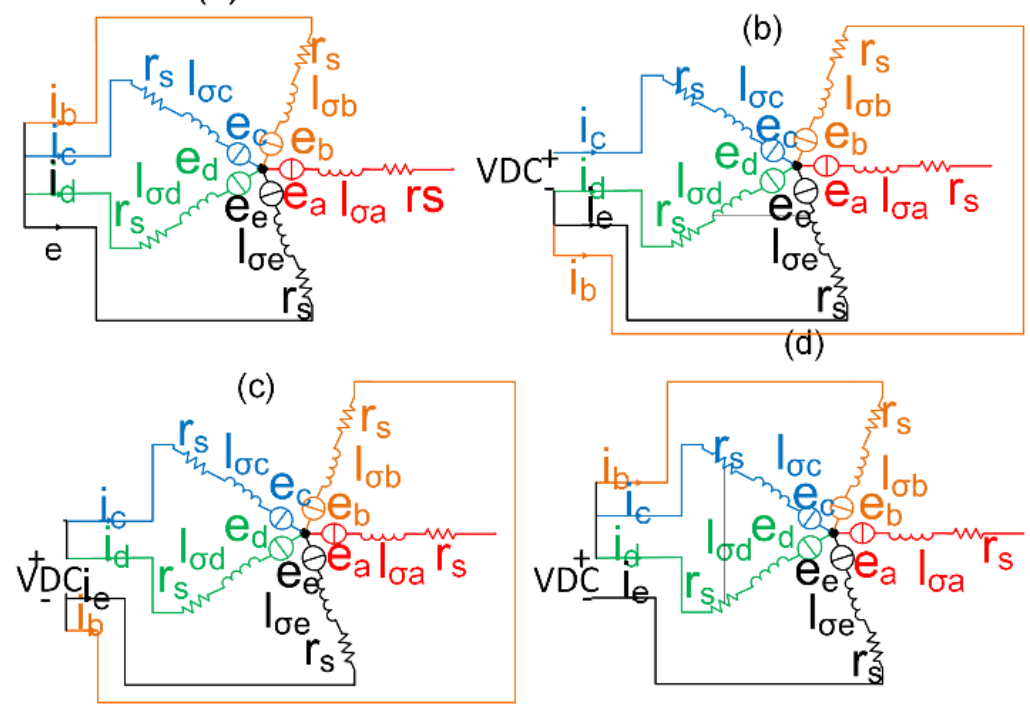

Figure11. Stator circuits when: (a) V0 is applied; (b) V2 is applied; (c) V11 is applied and (d) V6 is applied

Using the circuit in Figure 11.a and 11.b, the following equations hold true.

$$
\left[\begin{array}{c}
0 \\
V D C \\
0 \\
0
\end{array}\right]=r_{s} *\left[\begin{array}{l}
i_{b}{ }^{(V 2)}-i_{b}{ }^{(V 0)} \\
i_{c}{ }^{(V 2)}-i_{c}{ }^{(V 0)} \\
i_{d}{ }^{(V 2)}-i_{d}{ }^{(V 0)} \\
i_{e}{ }^{(V 2)}-i_{e}{ }^{(V 0)}
\end{array}\right]+\left[\begin{array}{l}
l_{\sigma b} * \frac{d}{d t}\left(i_{b}{ }^{(V 2)}-i_{b}{ }^{(V 0)}\right) \\
l_{\sigma c} * \frac{d}{d t}\left(i_{c}{ }^{(V 2)}-i_{c}{ }^{(V 0)}\right) \\
l_{\sigma d} * \frac{d}{d t}\left(i_{d}{ }^{(V 2)}-i_{d}{ }^{(V 0)}\right) \\
l_{\sigma e} * \frac{d}{d t}\left(i_{e}{ }^{(V 2)}-i_{e}{ }^{(V 0)}\right)
\end{array}\right]+\left[\begin{array}{c}
e_{b}{ }^{(V 2)}-e_{b}{ }^{(V 0)} \\
e_{c}{ }^{(V 2)}-e_{c}{ }^{(V 0)} \\
e_{d}{ }^{(V 2)}-e_{d}{ }^{(V 0)} \\
e_{e}{ }^{(V 2)}-e_{e}{ }^{(V 0)}
\end{array}\right]
$$

Where $l_{\sigma b, c, d, e}$ are the stator leakage inductances and $e_{b, c, d, e}$ are the back emf.

The following equations are obtained using Figure 11.b and Figure 11.c:-

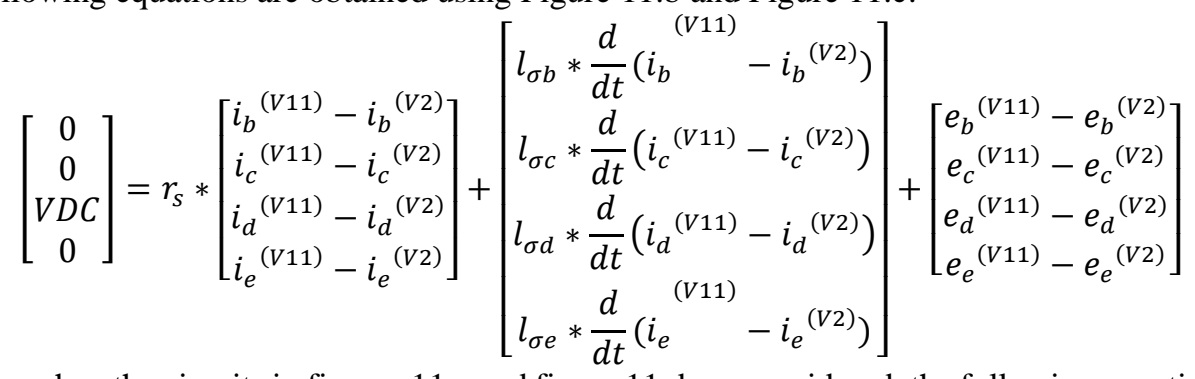

Finally when the circuits in figures 11.c and figure 11.d are considered, the following equations hold true:-

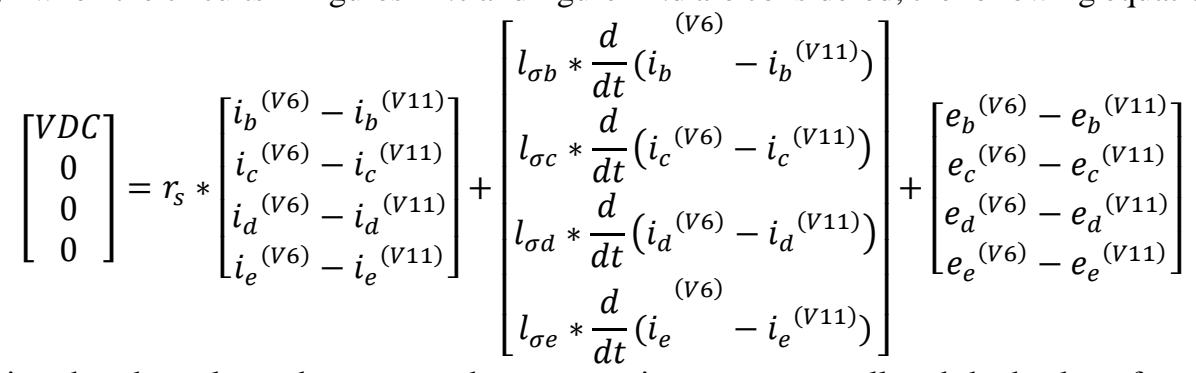

Assuming that the voltage drop across the stator resistances are small and the back emf can be neglected providing the time separation between the vectors is small, the following equations can be obtained using vector V0, V2,V11 and V6:- 


$$
\left[\begin{array}{l}
p a \\
p b \\
p c \\
p d
\end{array}\right]=\left[\begin{array}{l}
\frac{d i_{e}^{(V 2)}}{d t}-\frac{d i_{e}^{(V 0)}}{d t} \\
\frac{d i_{e}^{(V 11)}}{d t}-\frac{d i_{e}^{(V 2)}}{d t} \\
\frac{d i_{c}^{(V 6)}}{d t}-\frac{d i_{c}^{(V 11)}}{d t} \\
\frac{d i_{b}^{(V 11)}}{d t}-\frac{d i_{b}^{(V 2)}}{d t}
\end{array}\right]=\left[\begin{array}{l}
C 1 \\
C 1 \\
C 1 \\
C 1
\end{array}\right]+C 2 *\left[\begin{array}{c}
\cos (2 \theta) \\
\cos (2 \theta-72) \\
\cos (2 \theta-144) \\
\cos (2 \theta-216)
\end{array}\right]
$$

Where:-

$C 1=\frac{-\mathrm{v}_{D C} *\left(L_{S O}+L_{S l}\right)^{2}}{4\left(\left(L_{S O}+L_{S l}\right)^{3}\right.} \ldots \ldots \ldots \ldots . .$.
$C 2=\frac{-\mathrm{V}_{D C} * 1.618 *\left(L_{S o}+L_{S l}\right) * L_{x}}{4\left(\left(L_{S o}+L_{S l}\right)^{3}\right.}$.

Another example if the open circuit fault is introduced to phase ' $c$ ' and V_ref exists in the second sector. The PWM waveforms are shown in Figure 12.

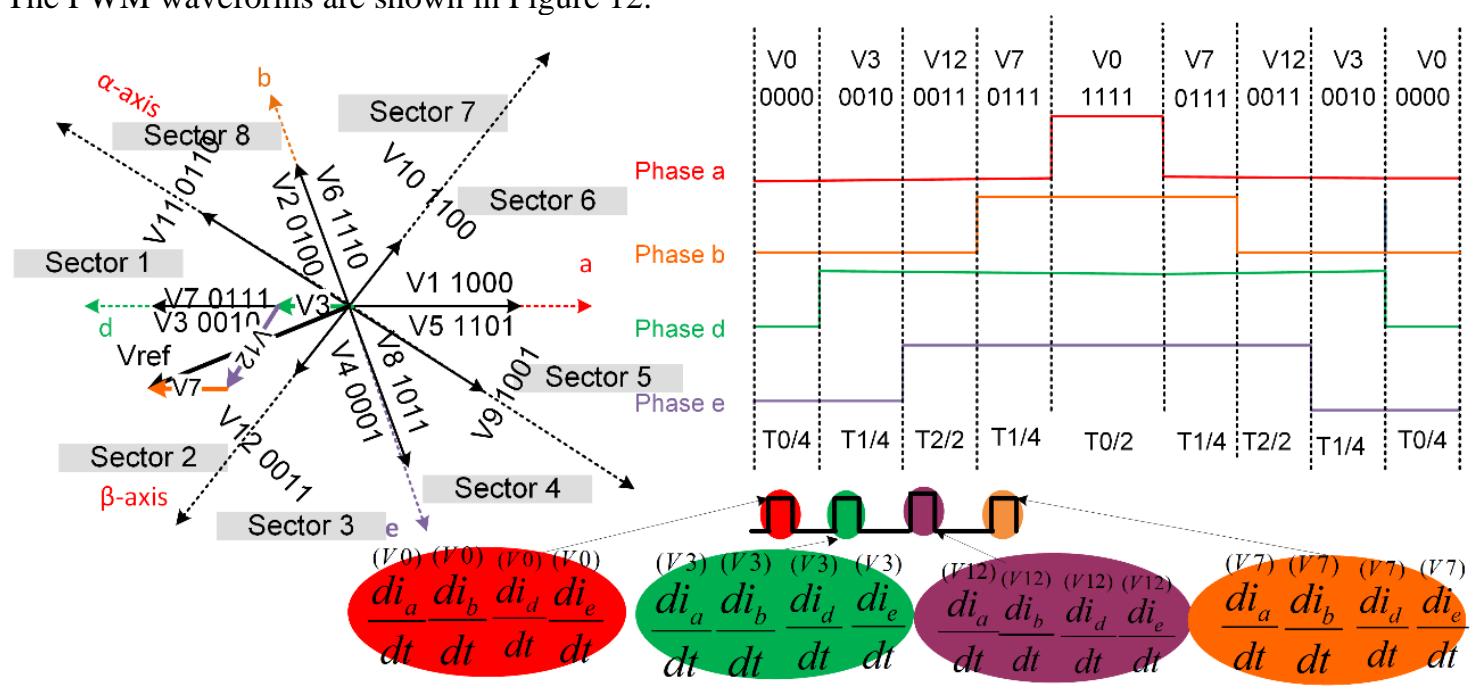

Figure 12. Sampling time of the currents transient eesponses in case of open-circuit fault in phase ' $c$ '.

Figure $13 \mathrm{a}$, figure $13 \mathrm{~b}$,figure $13 \mathrm{c}$ and figure $13 \mathrm{~d}$ show respectively the stator circuits when the vectors V0, V3,V12 and V7 are applied.
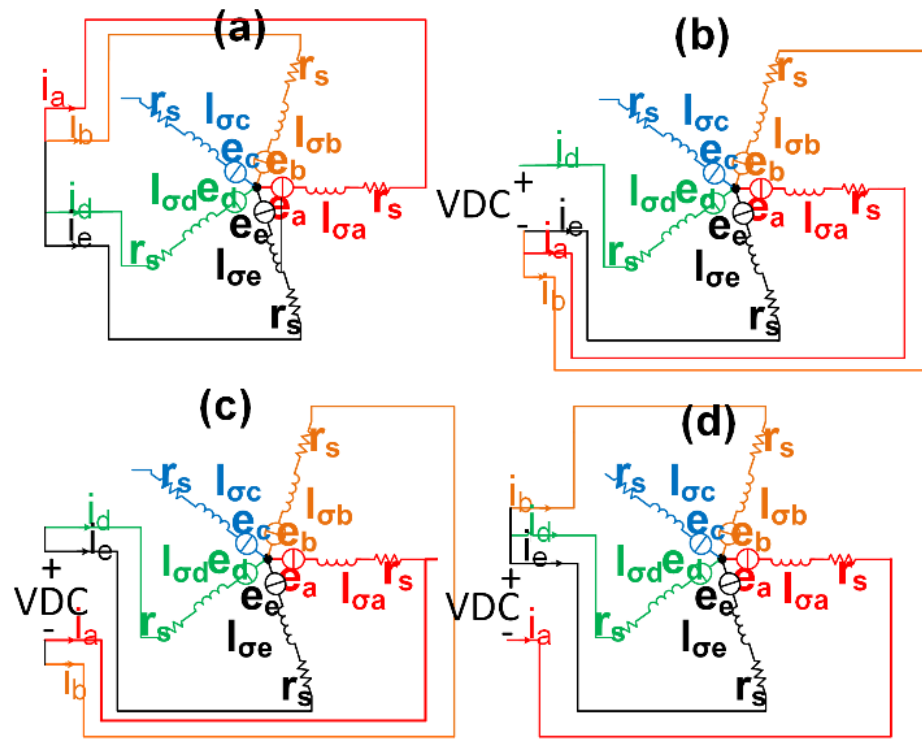

Figure13. Stator circuits when: (a) V0 is applied; (b) V3 is applied; (c) V12 is applied and (d) V7 is applied 
Using the circuit in Figure 13.a and 13.b, the following equations hold true.

$$
\left[\begin{array}{c}
0 \\
0 \\
V D C \\
0
\end{array}\right]=r_{s} *\left[\begin{array}{l}
i_{a}{ }^{(V 3)}-i_{a}{ }^{(V 0)} \\
i_{b}{ }^{(V 3)}-i_{b}{ }^{(V 0)} \\
i_{d}{ }^{(V 3)}-i_{d}{ }^{(V 0)} \\
i_{e}{ }^{(V 3)}-i_{e}{ }^{(V 0)}
\end{array}\right]+\left[\begin{array}{l}
l_{\sigma a} * \frac{d}{d t}\left(i_{a}{ }^{(V 3)}-i_{a}{ }^{(V 0)}\right) \\
l_{\sigma b} * \frac{d}{d t}\left(i_{b}{ }^{(V 3)}-i_{b}{ }^{(V 0)}\right) \\
l_{\sigma d} * \frac{d}{d t}\left(i_{d}{ }^{(V 3)}-i_{d}{ }^{(V 0)}\right) \\
l_{\sigma e} * \frac{d}{d t}\left(i_{e}{ }^{(V 3)}-i_{e}{ }^{(V 0)}\right)
\end{array}\right]+\left[\begin{array}{l}
e_{a}{ }^{(V 3)}-e_{a}{ }^{(V 0)} \\
e_{b}{ }^{(V 3)}-e_{b}{ }^{(V 0)} \\
e_{d}{ }^{(V 3)}-e_{d}{ }^{(V 0)} \\
e_{e}{ }^{(V 3)}-e_{e}{ }^{(V 0)}
\end{array}\right]
$$

The following equations are obtained using Figure 13.b and Figure 13.c:-

$$
\left[\begin{array}{c}
0 \\
V D C \\
0 \\
0
\end{array}\right]=r_{s} *\left[\begin{array}{l}
i_{a}{ }^{(V 12)}-i_{a}{ }^{(V 3)} \\
i_{b}{ }^{(V 12)}-i_{b}{ }^{(V 3)} \\
i_{d}{ }^{(V 12)}-i_{d}{ }^{(V 3)} \\
i_{e}{ }^{(V 12)}-i_{e}{ }^{(V 3)}
\end{array}\right]+*\left[\begin{array}{l}
l_{\sigma a} * \frac{d}{d t}\left(i_{a}{ }^{(V 12)}-i_{a}{ }^{(V 3)}\right) \\
l_{\sigma b} * \frac{d}{d t}\left(i_{b}{ }^{(V 12)}-i_{b}{ }^{(V 3)}\right) \\
l_{\sigma d} * \frac{d}{d t}\left(i_{d}{ }^{(V 12)}-i_{d}{ }^{(V 3)}\right) \\
l_{\sigma e} * \frac{d}{d t}\left(i_{e}{ }^{(V 12)}-i_{e}{ }^{(V 3)}\right)
\end{array}\right]+\left[\begin{array}{l}
e_{a}{ }^{(V 12)}-e_{a}{ }^{(V 3)} \\
e_{b}(V 12)-e_{b}{ }^{(V 3)} \\
e_{d}{ }^{(V 12)}-e_{d}{ }^{(V 3)} \\
e_{e}{ }^{(V 12)}-e_{e}{ }^{(V 3)}
\end{array}\right]
$$

Final when the circuits in figures 13.c and figure 13.d are considered, the following equations hold true:-

$$
\left[\begin{array}{c}
0 \\
0 \\
V D C \\
0
\end{array}\right]=r_{s} *\left[\begin{array}{l}
i_{a}{ }^{(V 7)}-i_{a}{ }^{(V 12)} \\
i_{b}{ }^{(V 7)}-i_{b}{ }^{(V 12)} \\
i_{d}{ }^{(V 7)}-i_{d}{ }^{(V 12)} \\
i_{e}{ }^{(V 7)}-i_{e}{ }^{(V 12)}
\end{array}\right]+*\left[\begin{array}{l}
l_{\sigma a} * \frac{d}{d t}\left(i_{a}{ }^{(V 7)}-i_{a}{ }^{(V 12)}\right) \\
l_{\sigma b} * \frac{d}{d t}\left(i_{b}{ }^{(V 7)}-i_{b}{ }^{(V 12)}\right) \\
l_{\sigma d} * \frac{d}{d t}\left(i_{d}{ }^{(V 7)}-i_{d}{ }^{(V 12)}\right) \\
l_{\sigma e} * \frac{d}{d t}\left(i_{e}{ }^{(V 7)}-i_{e}{ }^{(V 12)}\right)
\end{array}\right]+\left[\begin{array}{l}
e_{a}{ }^{(V 7)}-e_{a}{ }^{(V 12)} \\
e_{b}{ }^{(V 7)}-e_{b}{ }^{(V 12)} \\
e_{d}{ }^{(V 7)}-e_{d}{ }^{(V 12)} \\
e_{e}{ }^{(V 7)}-e_{e}{ }^{(V 12)}
\end{array}\right]
$$

Assuming that the voltage drop across the stator resistances are small and the back emf can be neglected providing the time separation between the vectors is small, the following equations can be obtained using vector V0, V3,V12 and V7:-

$$
\left[\begin{array}{l}
p a \\
p b \\
p c \\
p e
\end{array}\right]=\left[\begin{array}{ll}
\frac{d i_{a}^{(V 7)}}{d t}-\frac{d i_{a}^{(V 12)}}{d t} \\
\frac{d i_{d}^{(V 12)}}{d t}-\frac{d i_{d}^{(V 3)}}{d t} \\
\frac{d i_{a}^{(V 12)}}{d t}-\frac{d i_{a}^{(V 3)}}{d t} \\
\frac{d i_{b}^{(V 7)}}{d t}-\frac{d i_{b}^{(V 12)}}{d t}
\end{array}\right]=\left[\begin{array}{l}
C 1 \\
C 1 \\
C 1 \\
C 1
\end{array}\right]+C 2 *\left[\begin{array}{c}
\cos (2 \theta) \\
\cos (2 \theta-72) \\
\cos (2 \theta-144) \\
\cos (2 \theta-288)
\end{array}\right]
$$

The estimated position signals pa, pb, pc, pd in case of an open circuit fault in phase ' $\mathrm{c}$ ' is given in table1. The position scalar pe can be deduced from the scalars pa,pb, pc, and pe as follows:-

$$
p d=-(p a+p b+p c+p d)
$$


Table1 Selection of saturation saliency position scalars in PMSM motor post a phase'a' fault

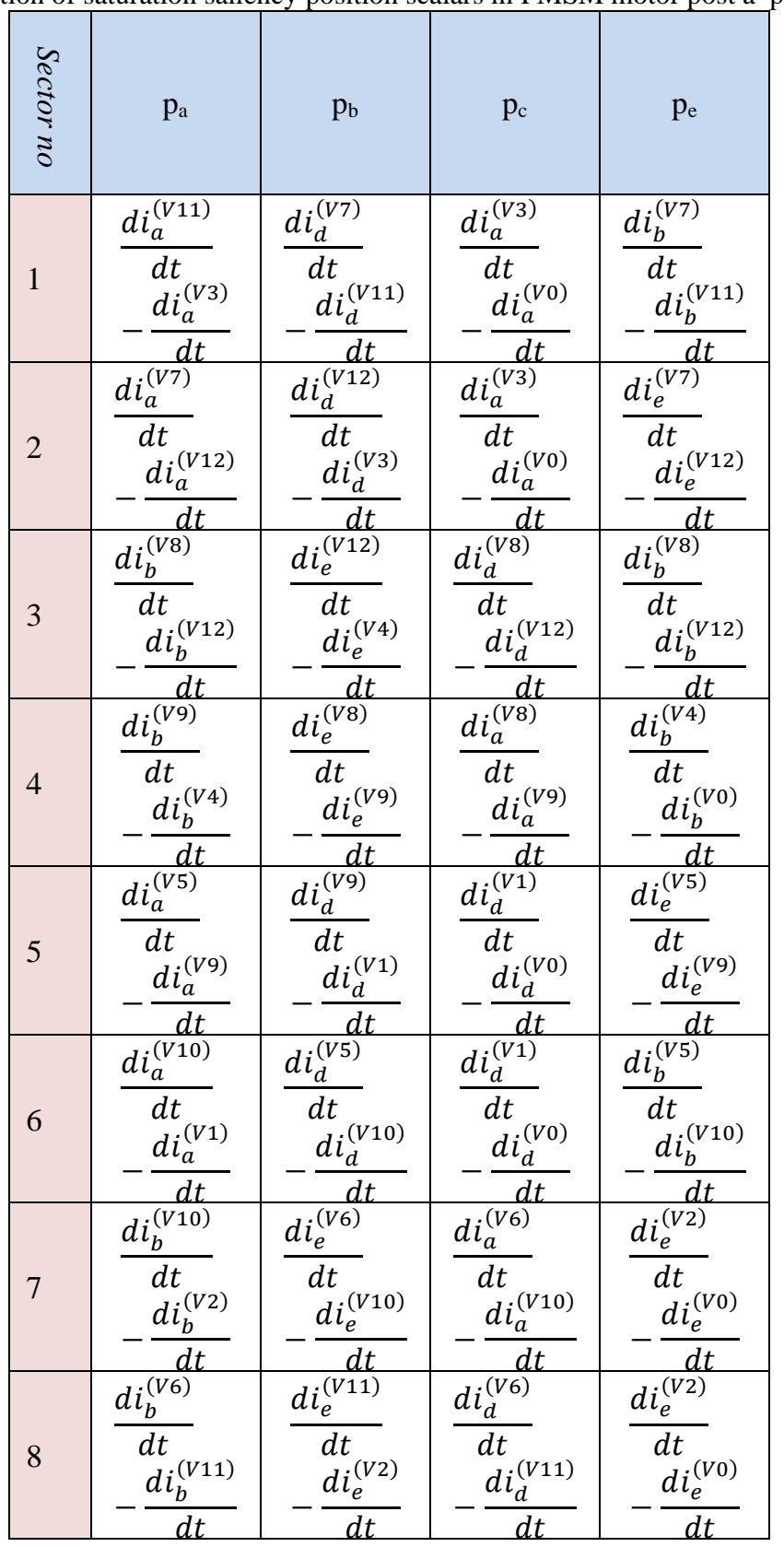

The estimated position signals in cases of an open circuit fault in phase 'a', 'b', 'd', and 'e' can be derived in the same ways.

Finally, the position signals $p_{\alpha}, p_{\beta}$ can be calculated as follows:-

$$
\begin{aligned}
& {\left[\begin{array}{l}
p_{\alpha} \\
p_{\beta}
\end{array}\right]=[V]\left[\begin{array}{c}
p a \\
p b \\
p c \\
p d \\
p e
\end{array}\right] \ldots \ldots \ldots(23) \quad, \quad \text { Where }} \\
& V=\left[\begin{array}{ccccc}
1 & \cos (2 * d) & \cos (4 * d) & \cos (6 * d) & \cos (8 * d) \\
0 & \sin (2 * d) & \sin (4 * d) & \sin (6 * d) & \sin (8 * d)
\end{array}\right] \ldots \ldots
\end{aligned}
$$

This technique is simulated in the SABER simulator and the results are illustrated in figure 14 . The results in time intervals $(0-2 s),(3 s-4 s),(5 s-6 s),(7 s-8 s)$ and $(9 s-10 s)$ are obtained while the motor was running normally while it was running under single-phase open-circuit fault at the rest of the test. The technique proposed in 
$[7,8]$ is used to track the saliency under healthy conditions while the technique proposed in this paper is used to track the saliency in five-phase PMSM motor post the fault. Figure 14 shows that the saliency of the PMSM motor pre and post the fault can be tracked with a good in both conditions.

\subsection{Sensorless Speed Control}

The control scheme to achieve a fully sensorless control of a five-phase PMSM is shown in figure 15 . In this control scheme, the algorithm proposed in [7,8] was used to track the saliency during normal operation ( position estimator under healthy condition block) while the algorithm proposed in this paper was used to track it post the fault (position estimator under faulty condition block). These two algorithms generated position signal scalars of the saliency $(\mathrm{P} \alpha \beta)$ that were noisy and hence a mechanical observer [27] was used to obtain a filtered speed signal $\omega^{\wedge}$ and a filtered position $\theta^{\wedge}$. And to make the simulation realistic, a minimum pulse width of 10us when di/dt measurements were made. The outputs of the mechanical observer were then used to obtain in sensorless vector control as shown in figure 15.

Figure 16, figure 17 and figure 18 show results of a different tests done on the five-phase PMSM motor at different conditions pre and post the fault. In figure 16, the motor was working in normal operating conditions and in sensorless mode at $30 \mathrm{rpm}$. A time $\mathrm{t}=3 \mathrm{~s}$, an open-circuit fault was introduced to phase ' $\mathrm{a}$ '. Then a speed step command from $30 \mathrm{rpm}$ to 0 at time $4 \mathrm{~s}$ was applied to the motor while phase ' $\mathrm{a}$ ' was opened. The motors responded to this step command. While the motor was running at zero speed and at time $\mathrm{t}=5 \mathrm{~s}$, the fault was removed from phase'a' and the motor returned to works in healthy operating conditions. At time $\mathrm{t}=7 \mathrm{~s}$, a singlephase open-circuit fault was introduced to phase' $b$ '. After that, at time $t=8 \mathrm{~s}$ a speed command from 0 to -30 rpm was applied to the motor. Figure 16 shows that the performance of the whole system pre and past the fault was the same.

Figure 17 demonstrates the ability of the motor to response to high speed command steps (from 0 to $300 \mathrm{rpm}$ and from $300 \mathrm{rpm}$ to $-300 \mathrm{rpm}$ ) post the fault with performance quality equals to that in healthy condition.

Figure 18 demonstrates the stability of the system under load disturbance application at low speed and post the fault.. The results show that the system maintains the speed in all the cases.

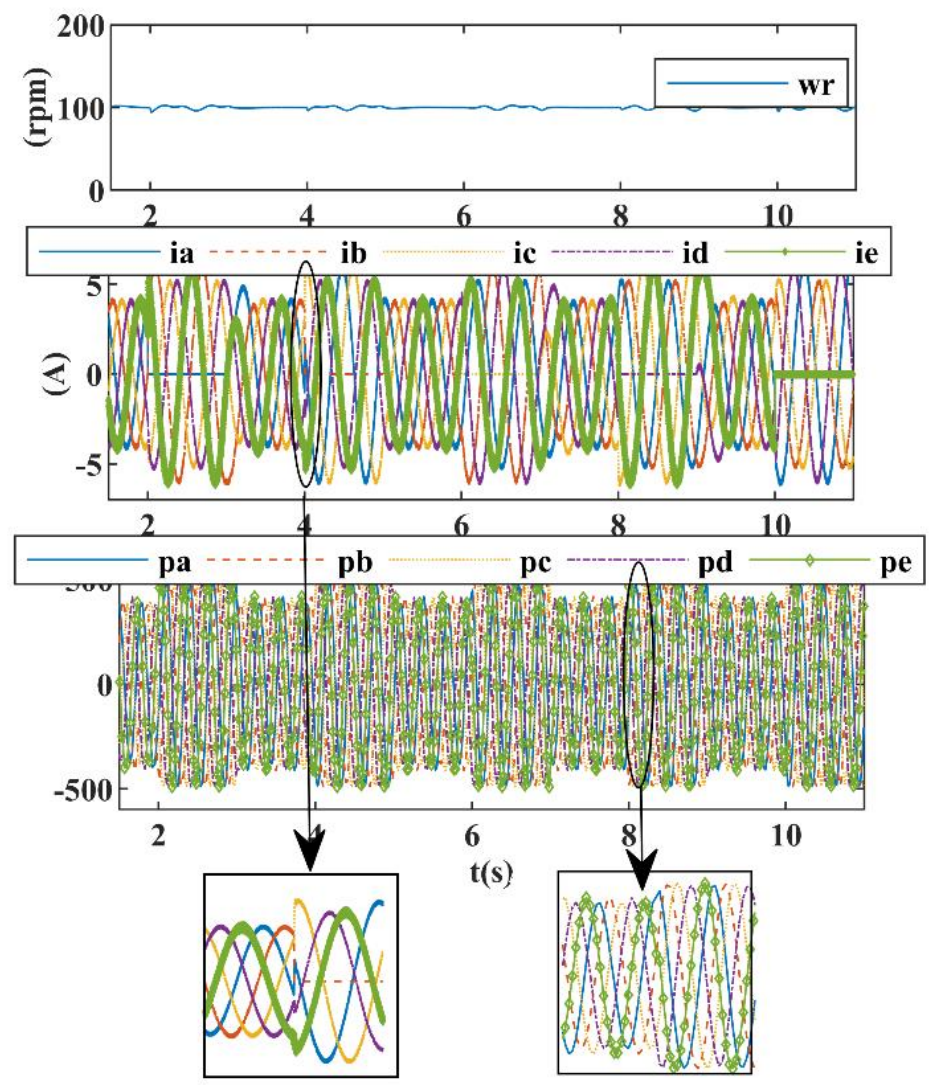

Figure 14 tracking the saturation saliency of five phase PM motor using the new algorithm post the fault . 


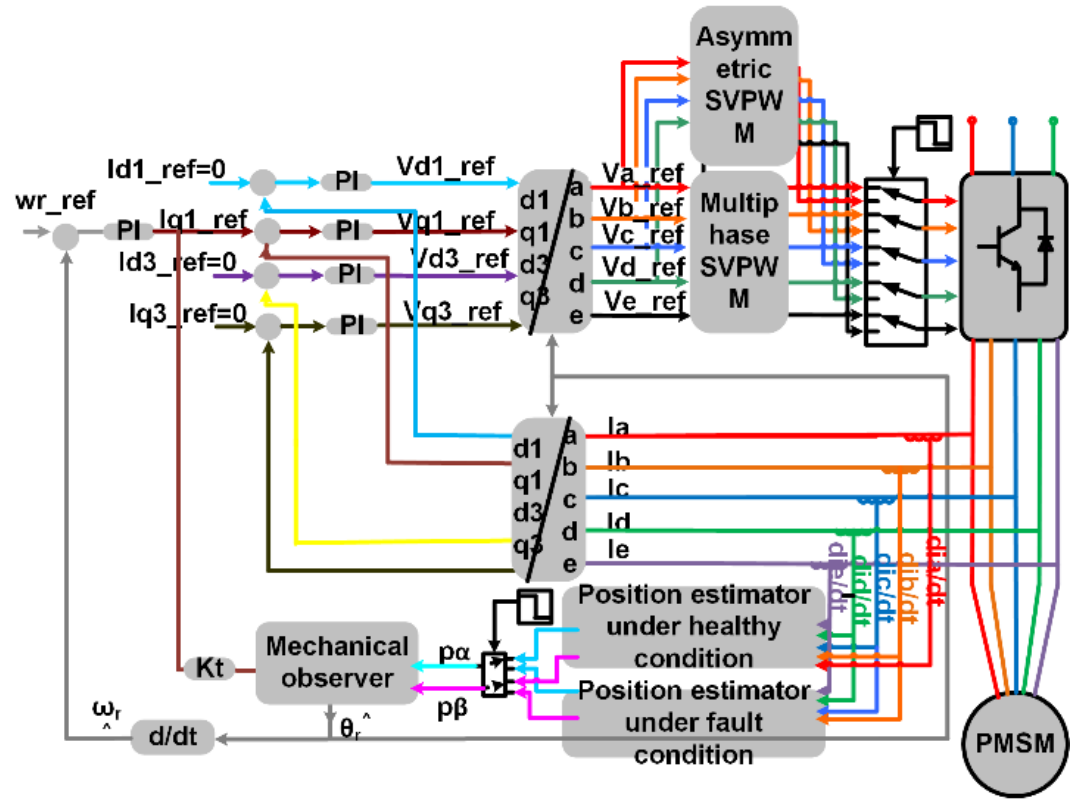

Figure 15 sensorless vector control schematic for a fault tolerant five phase drive.


Fig 16 . sensorless Speed Steps between $0.5 \mathrm{~Hz}, 0$ and $-0.5 \mathrm{~Hz}$ under healthy condition and under open phase a fault condition 

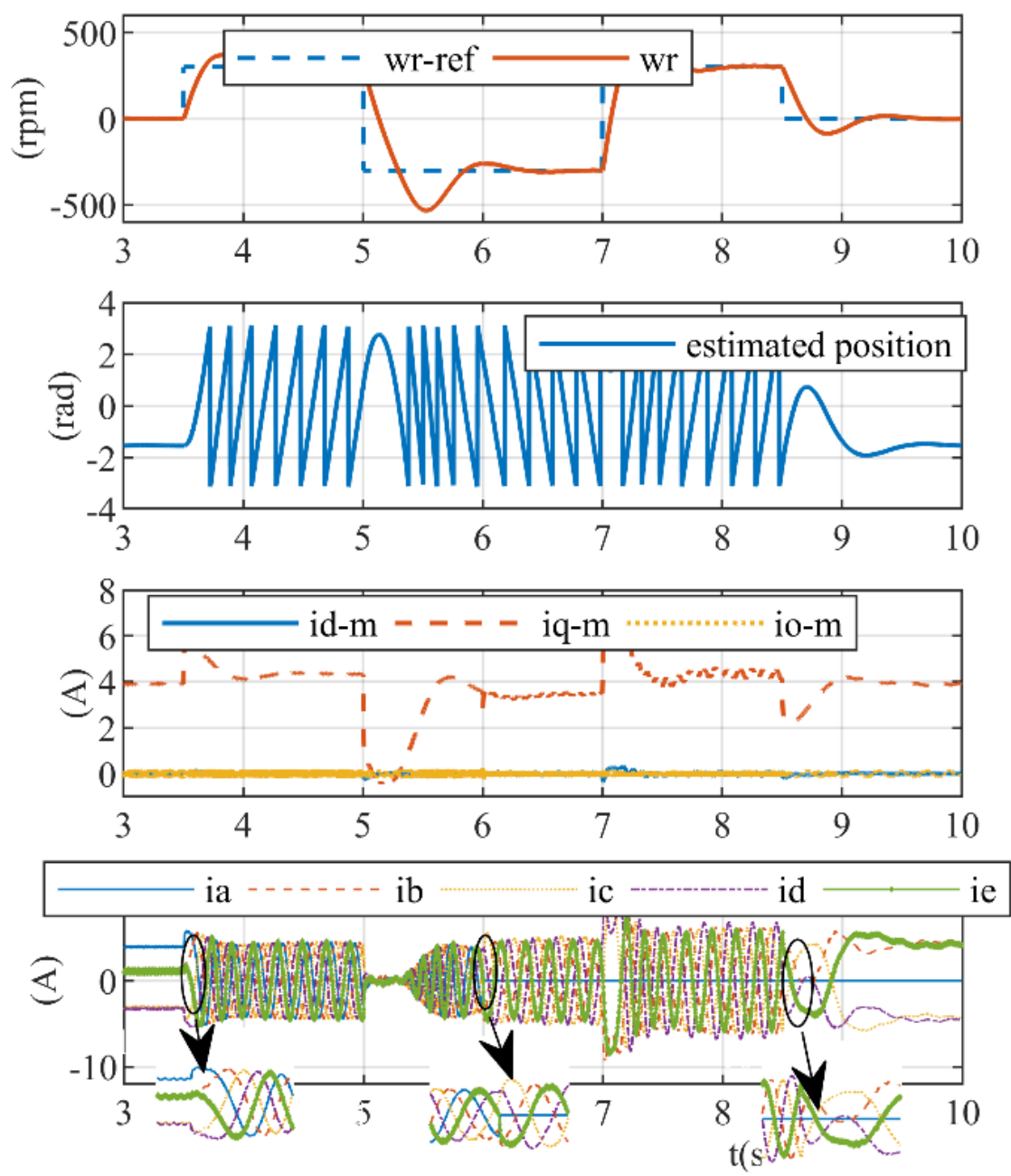

Fig 17 sensorless Speed Steps between $10 \mathrm{~Hz}, 0$ and $-10 \mathrm{~Hz}$ under healthy condition and under open phase

\section{Conclusion}

a fault condition

This paper has presented a novel technique to sensorless speed control five-phase PMSM drive post an open circuit fault. This drive can work under sensorless speed control at different load conditions under healthy operating conditions and in cases of an open circuit fault condition. The technique proposed in this paper includes software modification to the method proposed in [7,8] that works only when the motor is under a healthy operating condition. The new method is appropriate for tracking saturation saliency and rotor slotting saliency. The results have demonstrated the effectiveness of the new technique to track the saliency post the fault. 

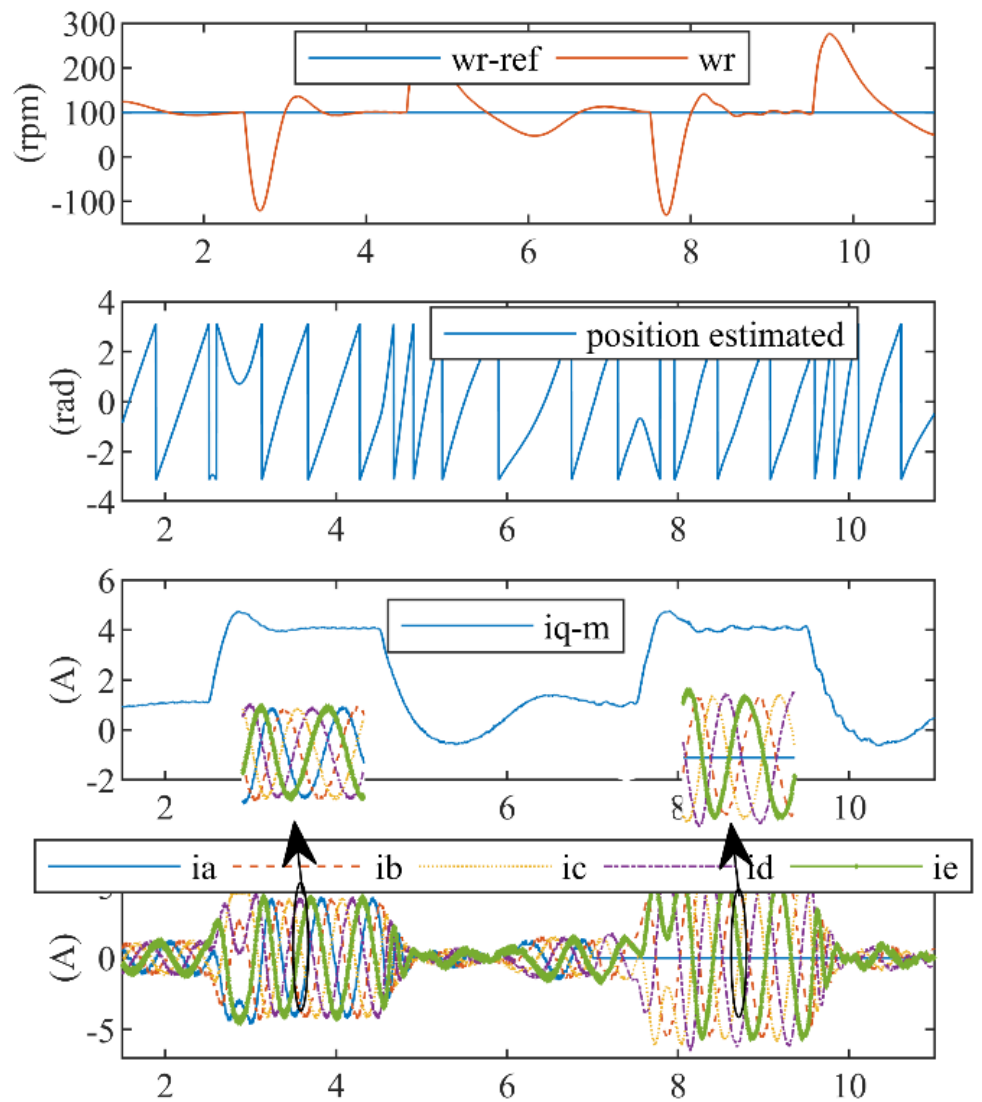

Fig 18 Fully Sensorless load Steps under healthy condition and under open phase a fault condition.

\section{REFERENCES}

[1] M. Villani, M. Tursini, G. Fabri and L. Castellini, Multi-phase fault tolerant drives for aircraft applications, Electrical Systems for Aircraft, Railway and Ship Propulsion, Bologna, 2010, pp. 1-6. doi: 10.1109/ESARS.2010.56652462

[2] Q. Song, X. Zhang, F. Yu and C. Zhang, Research on Space Vector PWM of Five-Phase Three-Level Inverter, International Conference on Electrical Machines and Systems, Nanjing, 2005, pp. 1418-1421. doi: 10.1109/ICEMS.2005.202782D.

[3] A. S. Morsy, A. S. Abdel-khalik, S. Ahmed and A. Massoud, Sensorless V/f control with MRAS speed estimator for a five-phase induction machine under open-circuit phase faults, 7th IEEE GCC Conference and Exhibition (GCC), Doha, 2013, pp. 268-273. doi: 10.1109/IEEEGCC.2013.6705788

[4] A. S. Abdel-Khalik, M. I. Masoud and B.W. Williams, Vector controlled multiphase induction machine: Harmonic injection using optimized constant gains, Electric Power Systems Research Journal, August 2012. Vol. 89, Pages 116-128, doi.org/10.1016/j.epsr.2012.03.001.

[5] L. Gao, J. E. Fletcher and L. Zheng, Low-Speed Cont rol Improvements for a Two-Level Five-Phase Inverter-Fed Induction Machine Using Classic Direct Torque Control, in IEEE Transactions on Industrial Electronics, July 2011.vol. 58, no. 7, pp. 2744-2754. doi: 10.1109/TIE.2010.2070775. 
[6] J. Riveros, F. Barrero, E. Levi, M. Durán, S. Toral, and M. Jones, Variable speed five-phase induction motor drive based on predictive torque control. IEEE Trans. Ind. Electron, Aug.2013.vol. 60, no. 8, pp. 2957--2968, doi: 10.1109/TIE.2012.2198034

[7] K.Saleh and M.Sumner. Modelling and simulation of a sensorless control of fve phase PMSM drives using multi dimension space vector modulation. In: TELKOMNIKA (telecommunication, computing, electronics and control). 2016. Vol 14, No 4. pp 1269-1283. doi.org/10.12928/TELKOMNIKA.v14i4.3996.

[8] K.saleh and M.Sumner, Sensorless speed control of five-phase PMSM drives with low current distortion. Springer Electrical engineering journal. June 2018, Volume 100, Issue 2, pp 357-374. doi.org/10.1007/s0020.

[9] K. A. Chinmaya and G. K. Singh, "Modeling and Comparison of Space Vector PWM Schemes for a Five- Phase Induction Motor Drive," IECON 2018 - 44th Annual Conference of the IEEE Industrial Electronics Society, Washington, DC, 2018, pp. 559-564. doi: 10.1109/IECON.2018.8591836.

[10] X. Liu, W. Kong, R. Qu and Q. Xu, "Non - Sinusoidal Power Supply Technology Based on Space Vector PWM for Multiphase Variable Speed Drives," 2018 IEEE Energy Conversion Congress and Exposition (ECCE), Portland, OR, 2018, pp. 319-324. doi: 10.1109/ECCE.2018.8558161

[11] L. Dong, M. Chang-bao, Z. Kun and Y. Long-ji, "Carrier based PWM with harmonics injection for multiphase induction motor drive," CSAA/IET International Conference on Aircraft Utility Systems (AUS 2018), Guiyang, 2018, pp. 1-7. doi: 10.1049/cp.2018.0143

[12] L. Parsa and H. A. Toliyat, Sensorless Direct Torque Control of Five-Phase Interior PermanentMagnet Motor Drives, in IEEE Transactions on Industry Applications, July-aug. 2007. vol. 43, no. 4, pp. 952-959. doi: 10.1109/TIA.2007.900444.

[13] B. Tian, G. Mirzaeva, Q. An, L. Sun and D. Semenov, "Fault-Tolerant Control of a Five-Phase Permanent Magnet Synchronous Motor for Industry Applications," in IEEE Transactions on Industry Applications, vol. 54, no. 4, pp. 3943-3952, July-Aug. 2018.doi: 10.1109/TIA.2018.2820060

[14] A. Mohammadpour, S. Sadeghi and L. Parsa, A Generalized Fault-Tolerant Control Strategy for FivePhase PM Motor Drives Considering Star, Pentagon, and Pentacle Connections of Stator Windings, in IEEE Transactions on Industrial Electronics, Jan. 2014. vol. 61, no. 1, pp. 63-75, doi: 10.1109/TIE.2013.2247011.

[15] J. Fu and T. A. Lipo, Disturbance free operation of a multiphase current regulated motor drive with an opened phase," Conference Record of the 1993 IEEE Industry Applications Conference TwentyEighth IAS Annual Meeting, Toronto, Ontario, Canada, 1993, vol.1, pp. 637-644. doi: 10.1109/IAS.1993.298884 A.

[16] T. S. de Souza, I. A. Pires and B. J. C. Filho, "Indirect Field Oriented Control of an Unbalanced Nine-Phase Induction Motor due to Open Phases," 2018 IEEE Industry Applications Society Annual Meeting (IAS), Portland, OR, 2018, pp. 1-8. doi: 10.1109/IAS.2018.8544515

[17] T. S. de Souza, R. R. Bastos and B. J. Cardoso Filho, "Modeling and Control of a Nine-Phase Induction Machine With Open Phases," in IEEE Transactions on Industry Applications, vol. 54, no. 6, pp. 6576-6585, Nov.-Dec. 2018. doi: 10.1109/TIA.2018.2852282

[18] Q. Chen, G. Liu, W. Zhao, L. Qu and G. Xu, Asymmetrical SVPWM Fault-Tolerant Control of Five-Phase PM Brushless Motors," in IEEE Transactions on Energy Conversion, March 2017. vol. 32, no. 1, pp. 12-22,.doi: 10.1109/TEC.2016.2611620

[19] H. Guzmán, M. J. Durán, F. Barrero and S. Toral, Fault-tolerant current predictive control of fivephase induction motor drives with an open phase, IECON 2011 - 37th Annual Conference of the IEEE Industrial Electronics Society, Melbourne, VIC, 2011, pp. 3680-3685. doi: 10.1109/IECON.2011.6119907 
[20] I. González-Prieto, M. J. Duran, N. Rios-Garcia, F. Barrero and C. Martín, "Open-Switch Fault Detection in Five-Phase Induction Motor Drives Using Model Predictive Control," in IEEE Transactions on Industrial Electronics, vol. 65, no. 4, pp. 3045-3055, April 2018. doi: 10.1109/TIE.2017.2748052

[21] D. G. Holmes, B. P. McGrath and S. G. Parker, Current Regulation Strategies for Vector-Controlled Induction Motor Drives, in IEEE Transactions on Industrial Electronics, Oct. 2012, vol. 59, no. 10, pp. 3680-3689, doi: 10.1109/TIE.2011.2165455.

[22] A. S. Abdel-Khalik, M. Hamad, S. Ahmed and A. Massoud, Effect of stator winding connection on performance of five-phase Linear Induction Machines, 8th IET International Conference on Power Electronics, Machines and Drives (PEMD 2016), Glasgow, 2016, pp. 1-5. doi: 10.1049/cp.2016.0269.

[23] S. M. Dabour and M. I. Masoud, Open-circuit fault detection of five-phase voltage source inverters,2015 IEEE 8th GCC Conference \& Exhibition, Muscat, 2015, pp. 1-6. doi: 10.1109/IEEEGCC.2015.7060049

[24] W. Zhang, D. Xu, P. N. Enjeti, H. Li, J. T. Hawke and H. S. Krishnamoorthy, Survey on Fault-Tolerant Techniques for Power Electronic Converters, in IEEE Transactions on Power Electronics, Dec. 2014, vol. 29, no. 12, pp. 6319-6331, doi: 10.1109/TPEL.2014.2304561.

[25] S. Chandrasekaran, C. Rossi, D. Casadei and A. Tani, Improved control strategy of wind turbine with DFIG for Low Voltage Ride Through capability,International Symposium on Power Electronics Power Electronics, Electrical Drives, Automation and Motion, Sorrento, 2012, pp. 19-24. doi: 10.1109/SPEEDAM.2012.6264552

[26] K.Saleh and M.Sumner. Sensorless Speed Control of Five-Phase PMSM Drives in Case of a SinglePhase Open-Circuit Fault. Iranian Journal of Science and Technology, Transactions of Electrical Engineering. Springer 2019. Vol 43, pp 1-17. doi:10.1007/s40998-018-00173-4

[27] R. D. Lorenz and K. W. Van Patten, High-resolution velocity estimation for all-digital, AC servo drives, in IEEE Transactions on Industry Applications, July-Aug. 1991, vol. 27, no. 4, pp. 701-705, doi: $10.1109 / 28.85485$ 